\title{
Individual Characteristics and The Gateway Hypothesis Among Drug User Patient In Indonesia
}

\author{
Aryo Galih Saloko',2, Asfi Manzilati1 \\ 1) Department of Economic Science, Faculty of Economics and Business, Universitas Brawijaya, Indonesia \\ 2) Badan Narkotika Nasional, Indonesia \\ guegalihmen@gmail.com
}

DOI: http://doi.org/10.29080/jhsp.v5i2.533

Received : Mei 2021, Accepted : Agustus 2021, Published : September 2021

\begin{tabular}{|c|c|}
\hline Keywords & Abstract \\
\hline $\begin{array}{l}\text { individual characteristics; } \\
\text { gateway hypothesis; } \\
\text { reversal pattern; } \\
\text { drug use; }\end{array}$ & $\begin{array}{l}\text { Drug abuse has become severe not just in the world but also in Indonesia. To address this } \\
\text { problem, public policies and researcher try to understand the drug use pattern. One of the } \\
\text { famous concept in drug use pattern is gatheway hypothesis. The gateway hypothesis } \\
\text { refers to the pattern of substance use initiate softer drug lead to the harder drug. } \\
\text { However, many literature shows drug use pattern is not just gateway pattern, there is } \\
\text { reversal pattern and using both gateway and reversal pattern. Many studies have } \\
\text { discussed the relationship between drug use and individual characteristics. However, few } \\
\text { of them are relatively link between individual characteristics and the sequential order in } \\
\text { drug use. The purpose of this study is to evaluate how individual characteristics are } \\
\text { associated with the gateway pattern and other pattern for different types of drugs. We } \\
\text { use a secondary dataset of individual drug user patients from the Rehabilitation Center of } \\
\text { National Narcotics Board aged 14-67 years assessed using the Addiction Severity Index } \\
\text { (ASI), employing probit and multinominal logit model. Duration are associated with } \\
\text { initial soft drug user with gateway pattern. While alcohol use and have high education } \\
\text { level related with initial hard drug user with reversal pattern. Interestingly, duration and } \\
\text { alcohol use correlated with initial intermediate drug user with all kind of pattern. } \\
\text { Prevention and intervention efforts should be targeting high-risk characteristics of people } \\
\text { at an initial stage of drug use and progression to the next stage. }\end{array}$ \\
\hline
\end{tabular}

\section{Introduction}

Drug abuse has become severe in the world. The World Drug Report 2019 reports that as of 2017, 5.5 percent of adolescents and adults in the world have experienced drugs at least once in the lifetime. The number of individuals with drug use experience has increased by 30 percent from 2009 to 2017. The escalation happens due partly to a 10 percent world population growth in the aged 15-64 (1). In 2017, the Institute for Health Metrics and Evaluation estimated that globally more than half a million people have died as a result of drug abuse. The death cases are mostly related indirectly to HIV and Hepatitis C, while the rest are directly associated with drug abusers, especially overdoses.

Drug abuse is also threatening in Indonesia. The National Narcotics Board (BNN) reports that the number of people who use drugs at 3.37 million people in 2017 (2). However, the trend is declining, since the number of current user in 2012 is 4.7 percent, while that in 2017 is 2.9 percent. The total seizure of marijuana (soft drug) is an increase from 13.9 tons in 2016 (3) to 151.5 tons in 2017 (4). As for crystalline methamphetamine (intermediate drug), the amount is 2.63 tons and 3.8 tons in 2016 and 2017, respectively. Furthermore, the ecstasy (intermediate drug) hike almost doubled from 1.7 million tablets to 3 million tablets of ecstasy in just one year, along with other drugs. In 2017, there were 20 cases with 27 suspects and assets worth more than 7.7 million USD for suppression of money laundering related to narcotics crimes.

The starting point for overcoming the drug use issue is to understand people's drug preferences. Many studies have investigated the pattern of drug use. The traditional argument is that an individual who 
uses a drug in the present tends to have a hierarchical sequence pathway that an adolescent's early experience with alcohol or tobacco escalates to more addictive illicit drugs later in adulthood, which referred to as the "gateway hypothesis" (5)(6)(7). Later, the term has extended to include marijuana as a substance that leads to other drugs, such as cocaine and heroin (8). The gateway hypothesis, defined as a sequence for drug use, usually begins with cigarettes and alcohol, heading towards soft drugs, like marijuana, and then other hard drugs $(5,9)$.

Many studies support the gateway effect on the progression of drug use. Among them, some studies claim that soft drug, such as marijuana, has a significant role in escalating other harder drug use (10-15). However, there is a counter-argument against the gateway hypothesis. Several studies claim a "reversal gateway" sequence of substances, implying that drug users initiate illicit-to-licit or hard-to-soft drug sequence (5,9,16-19). The research in New Zealand (18) and the United States (19) shows that the sequence starts with the use of hard drugs before marijuana. The cross-national study (9) mentions that drug use rates in some countries are not affected by the prevalence of marijuana, which may be inconsistent with the gateway pattern from soft drugs to the hard drug. Given these contrasting arguments, understanding a sequential order in drug use initiation provides valuable information for policy regulators that target the prevention of illicit drug prevalence. Policies to prevent drug use initiation and progression from one drug to other drugs can be an active channel for preventing long-term drug prevalence (20).

This study empirically examines how individual characteristics relate to the sequential order in drug use, i.e., the gateway and reversal gateway patterns, in the following distinct ways from past studies. First, many studies have discussed the relationship between illicit drug use and individual characteristics, such as gender, age, education, and employment status $(6,21-27)$ and evaluated the validity of the gateway and reversal gateway arguments ((5), for a comprehensive review of the gateway hypothesis). However, the empirical literature on the link of individual characteristics to the gateway and reversal gateway patterns is relatively small. In addition to the first stage to start illicit drug use, understanding the later stage of the sequence is also crucial for policy regulators. This study attempts to fill the gap.

We divide all patients (drug users) into three subsamples: (i) patients who started drug use with the soft drug (marijuana), (ii) those who started with the intermediate drug (amphetamine), and (iii) those who started with hard drugs (heroin, cocaine, opiate, and benzodiazepine). Among patients who started with the soft drug in subsample (i), some extended the drug use from soft drugs to other drugs (intermediate or hard drugs) (gateway pattern), and others continued to use the only soft drug. The analysis of subsample (i) allows us to examine the association of the gateway pattern with individual characteristics for patients who started with a soft drug. Also, among patients who started with the hard drug in subsample (iii), some extended from hard drugs to other drugs (intermediate or soft drugs) (reversal gateway pattern), and others continued to use the only hard drug. The analysis of subsample (iii) enables us to examine the association of the reversal gateway pattern with individual characteristics for patients who started with the hard drug. Moreover, among patients who started with the intermediate drug in subsample (ii), some extend from intermediate drug to soft or/and hard drug, and others continued to use only the intermediate drug. The patients with the former pattern can be further classified into four groups, (ii.a) patients who currently use hard drugs, (ii.b) patients who currently use the soft drug, (ii.c) patients who currently use both the soft drug and hard drugs, and (ii.d) patients who continued to use the only intermediate drug.

This study applies probit and multinomial logit analyses. It should be noticed that our empirical analysis does not intend to discuss the choice of the gateway drug at the first stage, which is impossible to analyze due to the data unavailability of non-drug users in our database. Instead, our analysis discusses possible determinants of the choice of the sequential order of illicit drugs in the gateway and reversal gateway contexts.

\section{Methods}

In this study, the data collected from the individual patient of the BNN Rehabilitation Center from 2014 to 2018. The Rehabilitation Center of BNN is government facilities located at Bogor District, West Java Province, Indonesia. This data was restricted and the detailed description obtained by the interview method during the assessment process of prospective patients using the Addiction Severity Index (ASI). 
ASI is an instrument in interviews collecting individual data about drug use, health, and social problems of people with alcohol and other drug problems (28). There are 3,943 data individuals observation; however, due to the same individual, missing data, and we focus on single group drug use, only 2,291 individual data, where qualify for analysis.

This paper used probit regression and multinominal logit regression. The probit and logit model is a non-linear regression model that produces an equation where the dependent variable is categorical (29). This study attempts to investigate how gateway sequence (soft-to-hard and hard-to-soft) determined by individual characteristics for each of the three types of entry drugs. This examination helps understands the drug use preference pattern in Indonesian. This study used individual characteristics and, as main variables, to determine the initiation order of drug users. The logistic regression model takes the following form:

$$
\operatorname{Prob}\left(Y_{i}=1 \mid Z_{i}\right)=F\left(\alpha+Z_{i} \beta\right)
$$

Where $Y_{i}$ is a dummy variable that takes one if patient $i$ follows the gateway (or reversal) pattern and zero otherwise; $Z_{i}$ is a set of controls, and $F$ is the logistic distribution function. We apply the probit model for subsample 1 and 3 and subsample 2 using multinominal logit since it is categorical.

\section{Dependent Variables}

This research evaluates the pathway of drug use initiation sequence, corresponds with gateway theory, and reversed gateway. There are three models in this study; the first model is where the dependent for initial soft drug user and initial hard drug user. In the initial soft drug user, the dummies would be (1) if the initial soft drug user follows the gateway pattern and $(0)$ if the initial soft drug user progress to an only soft drug user. Next, for the initial hard drug user, the dummies are (1) if the initial hard drug user follows a reversal pattern, $(0)$ if the initial hard drug user progress to an only hard drug user.

In the second model, we focus on the initial intermediate drug user or subsample 2, there are four measurements, which are gateway pattern, reversal pattern, both gateway-reversal pattern, and neither gateway pattern nor reversal pattern. First, the dummy of intermediate drug with gateway pattern, (1) if the initial intermediate drug user follows gateway pattern, and $(0)$ if the entry drug intermediate progress to only intermediate drug use (no gateway). Then, the dummy of an intermediate drug with a reversal pattern, (1) if the initial intermediate drug user follows the reversal pattern, (0) if the initial intermediate drug user were progressing to only intermediate drug use (no reversal). Last, the dummy of intermediate drug with both of a gateway pattern and reversal pattern, (1) if the initial intermediate drug user follows both gateway and reversal pattern, and $(0)$ if the initial intermediate drug user progress to only intermediate drug use (no reversal and no gateway).

\section{Independent Variables}

To achieve the objectives of this study, we use individual characteristics as the main variables. The individual characteristic used in the model is gender, age, duration, alcohol use, religion, education level, marital status, job status, urban/rural, the area in the province, and arrival years. Gender is a binary variable, one if male and zero if otherwise. Next, age is represented by the years. Duration of drug use is represented by the years of individuals who consume drugs from the beginning until the latest use. The duration of drug use that less than six months considered to be 0 years, while six months or more categorized as one year. Next, alcohol consumption is represented by categorical variables; it will value one if using alcohol and zero if otherwise. The Religion variable classified into two categories: the value would be zero if Moslem one if otherwise. Education level categorized into three groups : (1) never go to school, or complete elementary school or completed junior high school (2) completed senior high school or completed diploma, and (3) completed under graduated and higher education. Job-status measured as a categorical variable; it is divided into three categories : (1) unemployed or student or housewife, (2) work in a private firm, and (3) work in a public firm. Next, Marital status categorized into three categories : (1) married, (2) single, and (3) divorce. The areas are dummy-variable labeled one if urban, and zero if otherwise. 


\section{Results}

Table 1. Probit regression results: subsamples 1 and 3 (initial SOFT users and initial HARD users)

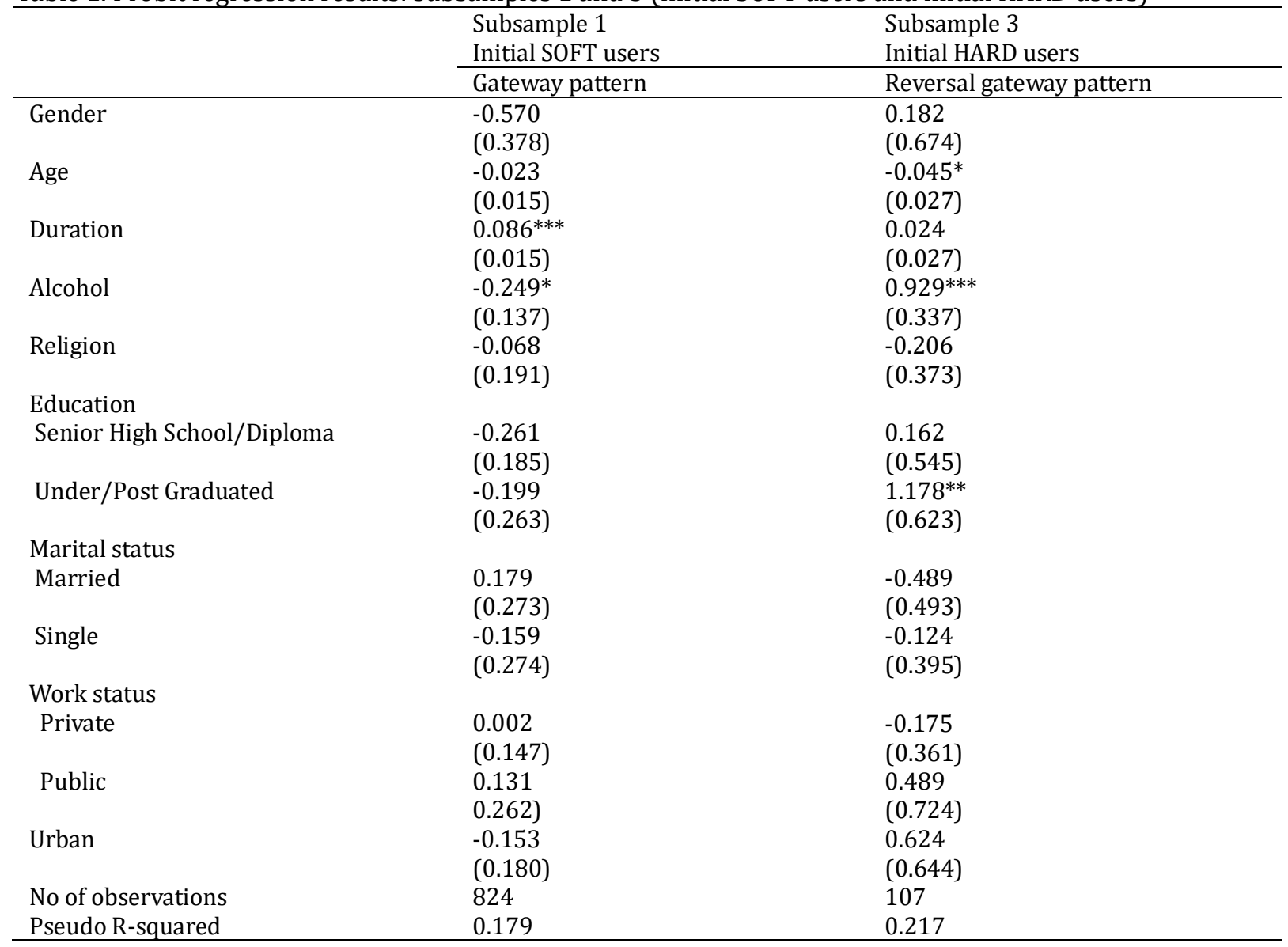

Notes: (1) The dependent variable is the gateway dummy (=1 if gateway pattern; $=0$ otherwise) in subsample 1 and the reversal gateway dummy (=1 if reversal gateway pattern; =0 otherwise) in subsample 2. (2) All models include the province dummies and year dummies. (3) ***, **, and * indicate the statistical significance at 1\%, 5\%, and 10\% levels, respectively. (4) Robust standard errors are in parentheses. 
Table 2. Multinomial logit regression results: Subsample 2 (initial INTE users)

\begin{tabular}{|c|c|c|c|}
\hline & Gateway only & Reversal gateway only & $\begin{array}{l}\text { Both gateway and } \\
\text { reversal gateway }\end{array}$ \\
\hline Gender & $\begin{array}{l}-0.493 \\
(0.475)\end{array}$ & $\begin{array}{l}0.845 \\
(0.550)\end{array}$ & $\begin{array}{l}0.850 \\
(0.894)\end{array}$ \\
\hline Age & $\begin{array}{l}-0.016 \\
(0.026)\end{array}$ & $\begin{array}{l}-0.049^{* *} \\
(0.021)\end{array}$ & $\begin{array}{l}-0.094^{*} \\
(0.045)\end{array}$ \\
\hline Duration & $\begin{array}{l}0.059^{* *} \\
(0.029)\end{array}$ & $\begin{array}{l}0.098^{* * *} \\
(0.020)\end{array}$ & $\begin{array}{l}0.175^{* * *} \\
(0.041)\end{array}$ \\
\hline Alcohol & $\begin{array}{l}0.769^{* *} \\
(0.330)\end{array}$ & $\begin{array}{l}0.636^{* * *} \\
(0.204)\end{array}$ & $\begin{array}{l}1.467^{* * *} \\
(0.436)\end{array}$ \\
\hline Religion & $\begin{array}{l}-0.646 \\
(0.505)\end{array}$ & $\begin{array}{l}-0.020 \\
(0.250)\end{array}$ & $\begin{array}{l}-0.725 \\
(0.640)\end{array}$ \\
\hline \multicolumn{4}{|l|}{ Education } \\
\hline Senior High School/Diploma & $\begin{array}{l}-0.002 \\
(0.417)\end{array}$ & $\begin{array}{l}-0.307 \\
(0.256)\end{array}$ & $\begin{array}{l}-1.197^{* *} \\
(0.516)\end{array}$ \\
\hline Under/Post Graduated & $\begin{array}{l}-0.103 \\
(0.592)\end{array}$ & $\begin{array}{l}-0.736^{*} \\
(0.409)\end{array}$ & $\begin{array}{l}-0.683 \\
(0.735)\end{array}$ \\
\hline \multicolumn{4}{|l|}{ Marital status } \\
\hline Married & $\begin{array}{l}-0.140 \\
(0.514)\end{array}$ & $\begin{array}{l}-0.204 \\
(0.385)\end{array}$ & $\begin{array}{l}-2.468^{* * *} \\
(0.689)\end{array}$ \\
\hline Single & $\begin{array}{l}-0.259 \\
(0.559)\end{array}$ & $\begin{array}{l}0.064 \\
(0.398)\end{array}$ & $\begin{array}{l}-0.610 \\
(0.611)\end{array}$ \\
\hline \multicolumn{4}{|l|}{ Work status } \\
\hline Private & $\begin{array}{l}-0.433 \\
(0.375)\end{array}$ & $\begin{array}{l}-0.284 \\
(0.238)\end{array}$ & $\begin{array}{l}0.740 \\
(0.524)\end{array}$ \\
\hline Public & $\begin{array}{l}-0.624 \\
(0.697)\end{array}$ & $\begin{array}{l}-0.331 \\
(0.394)\end{array}$ & $\begin{array}{l}0.143^{*} \\
(0.856)\end{array}$ \\
\hline Urban & $\begin{array}{l}0.400 \\
(0.450)\end{array}$ & $\begin{array}{l}-0.063 \\
(0.229)\end{array}$ & $\begin{array}{l}0.567 \\
(0.561)\end{array}$ \\
\hline No of observations & 1323 & 1323 & 1323 \\
\hline Pseudo R-squared & 0.154 & 0.154 & 0.154 \\
\hline
\end{tabular}

Notes: (1) The dependent variable is the categorical variable (=0 if neither gateway nor reversal gateway; $=1$ if gateway only; =2 if reversal gateway only; =3 if both gateway and reversal gateway). (2) The base category is neither gateway nor reversal gateway (use only INTE). (3) All models include the province dummies and year dummies. (4) ***, **, and * indicate the statistical significance at 1\%, 5\%, and 10\% levels, respectively. (5) Robust standard errors are in parentheses.

\section{Discussion}

Table 1 shows the individual characteristics of the initial soft drug users and initial hard drug users. The coefficient of alcohol consumption is significantly negative in subsample 1 . Among patients who started with soft drugs, those who drink alcohol are more likely to use only soft drugs without hard drugs, which implies that alcohol drinkers are less likely to follow the gateway pattern. This finding is different with a study in Mexico (30) shows that, alcohol consumption will be increaseds when the soft drugs (marijuana) use decreased. It indicate that alcohol drinkers are less likely associated with soft drug use.

The coefficient of duration is significantly positive in subsample 1. It means that the longer duration of drug use is more likely to follow the gateway pattern. This finding is in line with the gateway hypothesis and its existing studies (6), they found that most teenagers drug users in the United States began with marijuana use then the longer the use drugs expand to other hard drugs.

The coefficient of high education level is significantly positive in subsample 3 . It implies that the initial hard drug user who has a high education level tends to follow the reversal pattern. This finding is in line with the study from United State (6), intermediate and hard drug users had lower education compare to soft drug user. Similarly, the coefficient of alcohol drinker in subsample 3 is significantly positive. It indicates that the initial hard drug user who consume alcohol more likely to follow the reversal pattern. This finding is equivalent with research from Kentucky University (31), alcohol use is increases the hard drug use (coccaine).

Further, in subsample 3, the coefficient of age is significantly negative. It implies that as age increase, a patient who uses the hard drug at the beginning is less likely to follows the reversal pattern. In this context, drug user remain to use hard drugs from the start until now. Consistent with one of study (32) which found that current regular hard drug (heroin) users within the United States finds that 20.3\% deviated from the gateway theory. Heroin user at an earlier age used heroin for a longer duration and used 
it more frequently.

Finally, we present the result of individual characteristics for an initial intermediate drug user in a sequential pattern in Table 2 . In the subsample 2 who follow the gateway pattern, the coefficient of alcohol consumption and duration is positive and significant. It implies that an initial intermediate drug user who uses alcohol and has a longer time in drug use tends to follow the gateway pattern. Similarly, in the subsample 2 who follow the reversal pattern, the coefficient of alcohol consumption and duration is positive and significant. Initial intermediate drugs user who drinks alcohol and has a longer duration of drug use is more likely to follow the reversal pattern. Binge drinking related with increased in intermediate drug (methamphetamine) use (33) and hard drug (cocaine) use (34).

However, the coefficient of the high level of education and age is significantly negative. It means that an individual who completed undergraduate or higher and more age had less possibility to follow the reversal pattern. Initial intermediate drug user who follow gateway pattern related with high level of education and age transition. It is still unclear the relationship between high education level and drug use. Possible explanation with the intermediate drug user and harder drug use with the high education level is people with high level of education have more financial support compare to the low level education. The price of intermediate and harder drugs is more expensive than soft drugs. Therefore people with high level of education have a high possibility to buy high cost drugs .

Then, in the subsample 2, which follow both gateway and reversal pattern, the coefficient of alcohol consumption and duration is positive and significant. It implies that an initial intermediate drug user who uses alcohol and has a longer time in drug use tends to follow both gateway and reversal patterns. This result is in line with a research in United States (33), alcohol drink is associated intermediate drugs. However, alcohol consumption is substitute for soft drug use in Mexico (30).

On the other hand, the coefficient age, middle education level, and married is significantly negative. It indicates that an initial intermediate drug user who has more age, completed senior high school or diploma, and married appears to decrease the likelihood of both gateway and reversal pattern. Interestingly, the coefficient of work in public firms is positive and significant. It means that people who begin to use the intermediate drug and work in public firms are more likely to follow both gateway and reversal patterns. Many reasons could be possibly ascribed to why working in public firms and initial intermediate drug use patterns related. First, the intermediate drug has high demand in Indonesia, and it can be seen with the number of seizures which increases from time to time. The intermediate drug became one of the popular drugs in this country besides soft drugs. Therefore, in general, working in public firms also could access this substance use. Another possibility is related to high-risk drug use exposure in public sectors, especially in law enforcement. However, there is less understanding surrounding the association of public services employees who exposure to the intermediate drug.

Relatively, alcohol drinker and have a longer duration of drug use is more likely of initial intermediate drug user of gateway pattern, reversal pattern, and both gateway and reversal pattern.

\section{Conclusion}

The determinant of individual characteristics for each class of drug use is heterogeneous. Overall, education, working status, age, marriage, alcohol use, and duration are associated with initial particular drug use and its progression with other drug use. The relationship between gateway pattern and individual characteristics was complex in this sample. The gateway pattern of soft drug user is related with duration. Surprisingly, an initial hard drug user who alcohor drinker, completes college and higher have a greater chance associated with the following reversal pattern. Alcohol and duration more likely associated with all pattern of intermediate drug user. Initial intermediate drug user who working in public sectors, married and have education in Senior High School or Diploma may have different pattern on the latest drugs use.

These findings suggest that prevention and intervention efforts targeting high-risk drinking alcohol may benefit from assessing whether they simultaneously use alcohol and drug. Knowing the pattern of progression by the individual characteristics can help to plan-targeted interventions to reduce the adverse physical and social consequences of drug use disorders.

However, our study has some limitations. Given our sample is using a clinic-based population of treatment seekers, generalization could be biased. Next, we use simplification by put specific drug use into 
a group; therefore, there is a possibility the character of the single drug is less accurate. We also consider that we have not been able to quantify or perform the kind of research needed to explore possible causality why these pathways vary for different characteristics. Despite these limitations, the present study is the first study of the initiation of drug use and its progression in Indonesia.

\section{Acknowledgments}

Authors would like to thank Rehabilitation Center of Narcotics National Boards, which permitted us to analyze the data.

\section{References}

1. UNODC. World Drug Report 2019 [Internet]. United Nations. Vienna; 2019. Available from: https://wdr.unodc.org/wdr2019/prelaunch/WDR19_Booklet_1_EXECUTIVE_SUMMARY.pdf

2. National Narcotics Board. Executive Summary Survei Nasional Penyalahgunaan Narkoba Di 34 Provinsi Tahun 2017 [Executive Summary National Survey of Drug Abuse in 34 Provinces in 2017]. Jakarta; 2017.

3. Kanato M, Leyatikul P, Choomwattana C. ASEAN drug monitoring report 2016. ASEAN Narcotics Coop Cent [Internet]. 2017; Available from: https://asean.org/wpcontent/uploads/2016/10/Doc6-ADM-Report-2016-as-of-15-November-2017-FINAL.pdf

4. Kanato M, Leyatikul P, Choomwattana C. ASEAN drug monitoring report 2017. ASEAN Narcotics Coop Cent [Internet]. 2018;12-8. Available from: https://asean.org/wpcontent/uploads/2016/10/Doc6-ADM-Report-2016-as-of-15-November-2017-FINAL.pdf

5. Vanyukov MM, Tarter RE, Kirillova GP, Kirisci L, Reynolds MD, Kreek MJ, et al. Common liability to addiction and "gateway hypothesis": Theoretical, empirical and evolutionary perspective. Drug Alcohol Depend [Internet]. 2012;123(SUPPL.1):S3-17. Available from: http://dx.doi.org/10.1016/j.drugalcdep.2011.12.018

6. Nkansah-Amankra S, Minelli M. "Gateway hypothesis" and early drug use: Additional findings from tracking a population-based sample of adolescents to adulthood. Prev Med Reports [Internet]. 2016;4:134-41. Available from: http://dx.doi.org/10.1016/j.pmedr.2016.05.003

7. Moselhy HF. Gateway Hypothesis. Princ Addict. 2013;87-95.

8. Fergusson DM, Boden JM, Horwood LJ. Cannabis use and other illicit drug use: Testing the cannabis gateway hypothesis. Addiction. 2006;101(4):556-69.

9. Degenhardt, Dierker L, Chiu WT, Medina-mora ME, Sampson N, Alonso J, et al. Evaluating the drug use "gateway" theory using cross-national data. Drug Alcohol Depend. 2011;108(2):84-97.

10. Ellickson PL, Hays RD, Bell RM. Stepping Through the Drug Use Sequence: Longitudinal Scalogram Analysis of Initiation and Regular Use. J Abnorm Psychol. 1992;101(3):441-51.

11. Graham JW, Collins LM, Wugalter SE, Chung NK (Jacob., Hansen WB. Modeling Transitions in Latent Stage-Sequential Processes: A Substance Use Prevention Example. J Consult Clin Psychol. 1991;59(1):48-57.

12. Kandel DB. Examining the Gateway Hypothesis: Stages and Pathways of Drug Involvement. In D. Kandel (Ed.), Stages and Pathways of Drug Involvement: Examining the Gateway Hypothesis. University C, editor. Cambridge: Cambridge University Press. New York: Cambridge: Cambridge University Press; 2002. (pp. 3-16).

13. Yamaguchi K, Kandel DB. Patterns of drug use from adolescence to young adulthood: III. Predictors of progression. Am J Public Health. 1984;74(7):673-81.

14. Collins LM. Using Latent Transition Analysis to Examine the Gateway Hypothesis. Stages Pathways Drug Involv. 2009;254-69.

15. Lynskey MT, Vink JM, Boomsma DI. Early onset cannabis use and progression to other drug use in a sample of dutch twins. Behav Genet. 2006;36(2):195-200.

16. Golub, Johnson BD. Substance Use Progression and Hard Drug Use in Inner-City New York. Stages Pathways Drug Involv. 2009;90-112.

17. Mackesy-Amiti ME, Fendrich M, Goldstein PJ. Sequence of drug use among serious drug users: Typical vs atypical progression. Drug Alcohol Depend. 1997;45(3):185-96.

18. Wells JE, McGee MA. Violations of the usual sequence of drug initiation: Prevalence and associations with the development of dependence in the New Zealand Mental Health Survey. J Stud Alcohol Drugs. 2008;69(6):789-95.

19. Degenhardt, Chiu WT, Conway K, Dierker L, Glantz M, Kalaydjian A, et al. Does the 'gateway' matter? Associations between the order of drug use initiation and the development of drug dependence in the National Comorbidity Study Replication. NIH Public Access [Internet]. 2010;39(1):157-67. Available from: https://www.ncbi.nlm.nih.gov/pmc/articles/PMC2653272/pdf/nihms88815.pdf 
20. Deza M. Is there a stepping stone effect in drug use? Separating state dependence from unobserved heterogeneity within and between illicit drugs. J Econom [Internet]. 2015;184(1):193-207. Available from: http://dx.doi.org/10.1016/j.jeconom.2014.08.005

21. Chatterji P. ILLICIT Drug Use And Educational Attainment. NBER Work Pap Ser Illicit [Internet]. 2003; Available from: https://www.nber.org/papers/w10045.pdf

22. Crampton SM, Mishra JM, Zerfas DW. Employees' need for speed: Methamphetamine in the workplace. Health Care Manag (Frederick). 2008;27(2):131-6.

23. Mattson M, Lipari RN, Hays C, Horn SL Van. A day in the life of older adults: Substance use facts [Internet]. The CBHSQ Report: Center for Behavioral Health Statistics and Quality. Rockville, MD; 2017. Available

from: https://www.samhsa.gov/data/sites/default/files/report_2792/ShortReport-2792.pdf

24. Merline AC, O'Malley PM, Schulenberg JE, Bachman JG, Johnston LD. Substance Use among Adults 35 Years of Age: Prevalence, Adulthood Predictors, and Impact of Adolescent Substance Use. Am J Public Health. 2004;94(1):96-102.

25. Stoops WW, Tindall MS, Mateyoke-Scrivner A, Leukefeld C. Methamphetamine use in nonurban and urban drug court clients. Int J Offender Ther Comp Criminol. 2005;49(3):260-76.

26. Van Ours JC. Cannabis, cocaine and jobs. J Appl Econom. 2006;21(7):897-917.

27. Weber E, Blackstone K, Iudicello JE, Morgan EE, Grant I, Moore DJ, et al. Neurocognitive deficits are associated with unemployment in chronic methamphetamine users. Drug Alcohol Depend [Internet]. 2012;125(1-2):146-53. Available from: http://dx.doi.org/10.1016/j.drugalcdep.2012.04.002

28. Mclellan T, Carise D, Coyne TH, Jackson TR. Addiction Severity Index - 5th Edition Clinical / Training Version.

29. Breen R, Karlson KB, Holm A. Interpreting and understanding logits, probits, and other nonlinear probability models. Annu Rev Sociol. 2018;44(May):39-54.

30. Crost B, Guerrero S. The effect of alcohol availability on marijuana use: Evidence from the minimum legal drinking age. J Health Econ [Internet]. 2012;31(1):112-21. Available from: http://dx.doi.org/10.1016/j.jhealeco.2011.12.005

31. Marks KR, Pike E, Stoops WW, Rush CR. Alcohol Administration Increases Cocaine Craving But Not Cocaine Cue Attentional Bias. Alcohol Clin Exp Res. 2015;39(9):1823-31.

32. Woodcock, Lundahl, Stoltman, Greenwald. Progression to regular heroin use: Examination of patterns, predictors, and consequences. Physiol Behav [Internet]. 2017;176(5):139-48. Available from: https://www.ncbi.nlm.nih.gov/pmc/articles/PMC5541382/pdf/nihms884544.pdf

33. Bujarski S, Roche D, Lunny K, Moallem NR, Courtney KE, Allen V, et al. a Community Sample of Methamphetamine Users. 2015;127-32.

34. McKay JR, Alterman AI, Rutherford MJ, Cacciola JS, McLellan AT. The relationship of alcohol use to cocaine relapse in cocaine dependent patients in an aftercare study. J Stud Alcohol. 1999;60(2):17680 . 